\title{
Constituição e Evolução do Estado Brasileiro.
}

\author{
Dalmo de Abreu Dallari \\ Professor Titular de Direito do Estado na Faculdade \\ de Direito da Universidade de São Paulo
}

\section{A Formação do Estado Brasileiro.}

O Estado do Brasil nasceu em 1815, quando a colônia, que na realidade já vinha funcionando desde 1808 como sede do reino português, foi equiparada juridicamente à metrópole, passando à categoria de Reino, unido aos de Portugal e Algarves. interessante assinalar que a idéia de livrar o Brasil da condição de colônia, sem separá-lo de Portugal, partiu de um francês, o Príncipe de Talleyrand, tendo sido sugerida por ele aos representantes de Portugal no Congresso de Viena, realizado para estabelecer o novo equilíbrio mundial, após a derrota final de Napoleão. Transmitida a sugestão ao governo português, deu origem à carta de lei de 16 de dezembro de 1815, pela qual o Príncipe Regente D. João elevou "o Estado do Brasil à categoria e graduação de reino".

Entretanto, para que se compreenda a formação e a evolução do Estado brasileiro é indispensável ter em conta as experiências de colonização e governo, anteriormente efetuadas. E necessário, também, considerar que $o$ ato de 1815 foi apenas um momento, embora importantíssimo, de um longo processo, que deveria ainda superar várias etapas até que o Brasil se definisse completamente e se consolidasse como um verdadeiro Estado.

A rigor, pode-se dizer que desde o descobrimento, em 1500, até o ano de 1548 o Brasil foi tratado como simples reserva patrimonial, da qual não se esperava tirar grande proveito. Por essa razão o governo português entregou a particulares a tarefa de promover a ocupação e a exploração do território, sendo oportuno lembrar que vários desses particulares nem sequer procuraram tomar posse das terras brasileiras que haviam recebido em doação. Só bem mais tarde, depois de conhecida a possibilidade de extrair riquezas do solo e do 
subsolo brasileiros é que voltaram a ser feitas novas doações. Mas, já então, Portugal tinha grandes esperanças num possível proveito e as doações foram feitas a donatários bastante interessados e que se dispunham a contribuir para a fazenda pública, passando esta a exercer controle sobre as atividades econômicas desenvolvidas no Brasil. Isso, aliás, é que explica porque tendo havido fracasso quase total do sistema de capitanias hereditárias voltaram a ocorrer doações posteriormente.

O fato é que até as primeiras décadas do século XVII a estrutura jurídico-administrativa do Brasil sofreu inúmeras modificações, que podem ser interpretadas como demonstrações de interesse do governo português, mas que revelam, ao mesmo tempo, as dificuldades encontradas para tratar o Brasil como uma unidade. Em 1548 D. João III instituiu o Governo Geral do Brasil, o que, entretanto, esteve bem longe de significar a efetiva presença do Governador Geral e de seus auxiliares imediatos em todos os lugares do território brasileiro que exigissem a tomada de decisões importantes. A grande extensão do território e as dificuldades de comunicações não permitiam que isso acontecesse. À vista desse fato foi modificada a orientação, estabelecendo-se, no ano de 1572, duas sedes administrativas, uma na Bahia e outra no Rio de Janeiro. Isso também não deu bons resultados e já no ano de 1577 ocorria a reunificação da administração brasileira. Mais tarde, em 1607, haveria novo desdobramento, com a criação da "jurisdição do sul”, o que duraria até 1616, quando se dá, de novo, a unificação. Outra modificação, todavia, iria ser introduzida em 1621, quando se estabelece um Governo Geral para todo o Brasil, exceto para o então chamado Estado do Maranhão, que manteria relativa autonomia até a instituição do vice-reinado do Brasil.

E importante acentuar que essas constantes modificações já refletiam, em grande parte, a existência de uma diferenciação natural, que iria favorecer o desenvolvimento de acentuada diferenciação cultural, exigindo soluções diferentes de lugar para lugar. Foi precisamente tal situação que levou os líderes federalistas, no século XIX, a afirmar que a própria natureza já se havia encarregado de criar no Brasil todas as condições que impunham a implantação de um Estado Federal.

Em linhas muito gerais, verifica-se que durante o século XVIII o Brasil teve dois "pólos de desenvolvimento", quase que independentes entre si e, além disso, pouco dependentes de Portugal, de onde praticamente nada recebiam. Nas regióes 
Norte e Nordeste desenvolveram-se vários núcleos econômicos, que serviriam de base a lideranças políticas, tendo a posse da terra como fundamento da autoridade, o que ainda persiste até os dias de hoje. Na região Centro-Sul a grande quantidade de ouro e diamantes atraiu muito mais as atenções de Portugal, além de propiciar o desenvolvimento de núcleos culturais completamente diversos, atraindo aventureiros, criando condições para uma vida social intensa e favorecendo a formação de centros urbanos muito ricos, que rivalizavam entre si na ostentação da riqueza. Embora nesta região tenha sido muito mais intensa a presença de autoridades portuguesas, sobretudo através dos Vice-Reis e do aparato fazendário, tal presença não impediu que também aí se afirmassem lideranças políticas locais, uma vez que às autoridades portuguesas só interessava arrecadar o máximo possível e impedir manifestações de insubordinação.

Esse conjunto de circunstâncias favoreceu, e de certo modo até exigiu, o desenvolvimento de uma ampla autonomia municipal, em torno de lideranças regionais, pois inexistia uma autoridade central forte e constantemente presente, que participasse da solução dos problemas mais ou menos importantes que diariamente se apresentavam. Esses, em linhas gerais, foram os componentes básicos que se definiram na primeira fase da formação da ordem política e social brasileira.

\section{Nascimento do Estado Brasileiro.}

A mudança da corte portuguesa para o Brasil, em 1808, em busca da segurança que Portugal não the podia oferecer nem mesmo com o apoio da Inglaterra, impotente para conter as ofensivas napoleônicas, acelerou intensamente o processo de instituição do Estado brasileiro.

A simples presença da corte no Rio de Janeiro já era um fator de prestígio, além de permitir que a autoridade central participasse efetivamente da solução dos problemas brasileiros. Por outro lado, não havendo a perspectiva de um retorno imediato a Portugal, tornou-se necessário aparelhar a Colônia para que daqui pudessem ser dirigidos todos os negócios do Reino. Cria-se, então, uma situação paradoxal: a sede do Reino achava-se instalada em território colonial e daqui partiam as ordens para o povo que vivia no território metropolitano. Embora formalmente Portugal fosse a metrópole e o Brasil uma colônia sua, na prática tudo se passava como se 
fosse o contrário. Pouco a pouco os brasileiros foram aumentando sua influência sobre o Príncipe Regente e depois Rei, D. João, tendo inúmeros líderes brasileiros percebido que a situação era propícia para que o Brasil avançasse no sentido de se livrar do estatuto colonial.

$\mathrm{Na}$ verdade, entretanto, só a presença da corte no Brasil e a influência dos brasileiros não teriam sido suficientes para que se atingisse aquele objetivo, pelo menos num prazo muito curto. Mas, para felicidade dos brasileiros, houve uma conjunção de fatores, que determinou a precipitação dos acontecimentos. Com efeito, apagada no desastre de Waterloo a estrela fulgurante de Napoleão, reuniu-se o Congresso de Viena, em 1815, para que as grandes potências definissem o novo equilíbrio político do mundo ocidental. Nessa conjuntura, Portugal, militarmente fraco, tinha a seu favor a multiplicidade de territórios, convindo-lhe mostrar que o Brasil era muito mais do que uma colônia selvagem e sem recursos. A França, por sua vez, precisava reintegrar-se num sistema comercial poderoso e para atingir seu objetivo convinha-lhe apoiar as aspirações portuguesas, não sendo desprezível a hipótese de que vislumbrasse a possibilidade de negociações diretas com o Brasil, cujas potencialidades já conhecia. Isso tudo, somado à atitude dos representantes portugueses, que por simpatia ou conveniência também desejavam a valorização do Brasil, levou à emancipação jurídica almejada por muitos brasileiros e que seria um passo importante no sentido da emancipação política.

Ressaltando, exatamente, essa conjugação de fatores, observa HÉlio DE ALCÂNTARA AvELAR: "Muito concorreram para o fato que, juridicamente, encerrou nossa história colonial e fez nascer a nacionalidade brasileira a diligência do Conde da Barca, a conveniência momentânea do representante francês no Congresso de Viena, TALLEYRAND, e a atuacão do plenipotenciário português, Conde de Palmella" (História Administrativa e Econômica do Brasil, p. 192).

Assim foi que, por ato de 16 de dezembro de 1815, o Brasil deixou, de modo formal e solene, de ser colônia portuguesa, passando à categoria de Reino, unido aos de Portugal e do Algarve. Nessa data nasceu o Estado brasileiro. embora continuasse governado por um rei português. E Portugal passava a figurar entre as grandes potências, em grande parte pela União de Reinos, não obstante estivesse criando as condicões aue tornariam inevitável, em breve tempo, a separação política do Brasil. 


\section{Linhas Gerais da Evolução do Estado Brasileiro.}

Embora do ponto de vista das relações internacionais a nova situação do Brasil conviesse a Portugal, para os portugueses que lá viviam o fato foi visto como negativo. De um lado, a circunstância de serem governados à distância já suscitava descontentamentos, pois era inevitável a redução da eficiência da administração. De outro lado, havia um certo sentimento de humilhação, pois não lhes parecia razoável que do Brasil, que ainda pretendiam ver como colônia, viessem as decisões que deveriam cumprir. Daí sua crescente hostilidade em relação aos brasileiros, que, a seu ver, estavam impedindo a volta do Rei exatamente para garantirem a hegemonia brasileira.

A par disso, Portugal também recebia as idéias liberais, oriundas sobretudo da França, surgindo um poderoso movimento antiabsolutista, tendo por principal bandeira a idéia de Constituição e favorecido pelo descontentamento generalizado em relação ao monarca, que resistia aos apelos para que voltasse.

Foram essas as principais circunstâncias que determinaram a eclosão da Revolução Liberal de 1820, que teve início na cidade do Porto e posteriormente atingiu Lisboa. Em síntese, os liberais portugueses tinham duas aspirações: o juramento de uma Constituição pelo monarca e a restauração da hegemonia de Portugal, inclusive com o declarado objetivo de retorno do Brasil à condição de colônia. Num curto prazo há uma sucessão de acontecimentos importantes, que levariam à consolidação do Estado brasileiro. Na iminência de perder a Coroa portuguesa, D. João VI retorna a Portugal, deixando no Brasil, como Regente, o Príncipe D. Pedro, mas absolutamente consciente, como está expresso em inúmeras passagens de sua correspondência desse período, que estava perdendo a Coroa do Brasil.

Constantemente assediado pelos brasileiros e irritado com o procedimento dos portugueses, que da hostilidade ao Brasil e aos brasileiros passaram à hostilidade ao Príncipe Regente, D. Pedro chegou ao 7 de setembro de 1822, cortando as amarras jurídicas e políticas que ligavam o Brasil a Portugal, desfazendo-se a União de Reinos e confirmando-se o Brasil como Estado soberano e independente.

Viria em seguida, de modo conturbado, o ingresso do Brasil na vida constitucional. Ainda como Príncipe Regente, 
em 16 de fevereiro de 1822, D. Pedro havia convocado um Conselho de Procuradores, para cuidar da elaboração de uma Constituição para o Brasil. Depois de proclamada a Independência e tendo sido convocada uma Assembléia Geral Constituinte, foi revogada a anterior convocação do Conselho de Procuradores. Entretanto, pelo rumo que tomaram os acontecimentos, sentindo-se ofendido e diminuído em sua autoridade, concebida ainda à luz do absolutismo, D. Pedro I, já então Imperador, dissolveu a Assembléia Constituinte em 12 de novembro de 1823, sobretudo por não admitir o projeto de Constituição que ali tramitava e que era de cunho marcadamente liberal. E já no dia seguinte, em 13 de novembro, o Imperador criou um Conselho de Estado, com a atribuição de elaborar um projeto de Constituição que ele pudesse considerar conveniente.

Depois de pronto o projeto, não havendo uma Assembléia Constituinte mas desejando o Imperador que fosse ouvido o povo, para comprovar sua vocação liberal nem sempre confirmada, o referido projeto foi submetido à apreciação das Câmaras Municipais. Estas, ou por estarem realmente de acordo com seu conteúdo, ou por desejarem que o Brasil tivesse logo uma Constituição, ou, quem sabe, por temerem as iras do Imperador, manifestaram-se inteiramente favoráveis ao projeto, pedindo que ele fosse convertido em Constituição sem mais tardança. Entre as mais veementes manifestações de aprovacãa estão a da Câmara da Bahia e a da Câmara de Itu, na Província de São Paulo, cidade esta que, anos mais tarde, exerceria papel de grande relevo na luta pela proclamação da República no Brasil.

Estando, por esse modo, assegurado da vontade dos brasileiros, D. Pedro I outorgou ao Brasil sua primeira Constituição, em 25 de março de 1824. Como se verifica, o Brasil iniciou de maneira dúbia sua vida constitucional. Com efeito, a dissolução da Assembléia Geral Constituinte e a outorga pelo Imperador dão ao documento a característica de Carta Outorgada, no sentido de norma fundamental imposta pela vontade do detentor do poder. Mas, ao mesmo tempo, os pronunciamentos das Câmaras Municipais a favor do projeto significam a concordância prévia do povo, através de seus representantes, mesmo que se diga que aquelas Câmaras não tinham poder constituinte.

Essa Constituição seria a de vida mais longa de quantas o Brasil já teve, pois ficaria em vigor até a proclamação da 
República, em 15 de novembro de 1889, quando foi revogada pelo decreto número 1 do Governo Provisório. Mas é preciso lembrar que as antigas autonomias políticas regionais e locais não se enquadraram pacificamente na estrutura do Estado Unitário consagrada na Constituição de 1824. O Imperador teve que enfrentar inúmeras manifestações de rebeldia, que o levaram à abdicação e à instauração de Regências, para governar o Brasil até que o herdeiro da Coroa atingisse a maioridade. $\mathrm{E}$ durante o período regencial, através do Ato Adicional de 1834, foi devolvida uma parte da autonomia às Províncias, sobretudo com a criação das Assembléias Provinciais, embora estas devessem conviver com um Governador de livre escolha do governo central. Mas as aspirações autonomistas continuaram vivas e a partir de 1870 , quando se desencadeia o Movimento Republicano, fala-se constantemente em federalismo e autonomia municipal. Estas duas aspirações vão ter acolhida na primeira Constituição republicana, de 1891, iniciando-se então o Brasil como Estado Federal, o que para muitos significou apenas a restauração da situação anterior à vinda da Família Real para o Brasil.

Depois disso vem a experiência republicana e federativa, cheia de percalços e, sobretudo, reveladora da inadequação entre as exigências da realidade social e a organização formal declarada na Constituição. Em grande parte, essa inadequação deveu-se ao fato de que o federalismo foi visto e buscado, quase que exclusivamente, como forma de promover a descentralização política, para que se fortalecessem as lideranças estaduais, à custa do esvaziamento das competências do governo central. Não foi devidamente considerada a circunstância de que a atribuição de maiores competências aos governos estaduais representava também a atribuição de mais encargos, o que, por sua vez, exigia maiores rendas. A falta de atenção para essa importante correlação fez que, desde o início da vida republicana, os Estados se revelassem incapazes de cumprir seus encargos. Essa deficiência, aliada a outros fatores, como a supervalorização das chefias políticas de alguns Estados, determinou que, em 1926, através de uma grande emenda constitucional, se tentasse disciplinar o exercício das autonomias estaduais. Mas a tentativa foi tardia e tímida, encerrando-se pouco depois, com a deposição do Presidente Washington Luiz e a revogação da Constituição em 1930, a primeira fase da vida republicana brasileira, deixando uma imagem desfavorável do federalismo. 
Em 1934, com nova Constituição, desta vez, como em 1891, elaborada e aprovada por uma Assembléia Constituinte, procedeu-se à restauração federativa, tentando-se corrigir as falhas anteriormente reveladas, mas incorrendo em outras inadequações, sobretudo por não terem sido devidamente integradas na organização político-constitucional as novas forças sociais, resultantes do ingresso do Brasil na era industrial. A par disso, foram totalmente preservadas as estruturas obsoletas e retrógradas do Norte e do Nordeste, ampliando-se o desnível entre as diferentes regiões brasileiras. Isso tudo levou à implantação da contraditória "ditadura constitucional" de 1937, com o ditador Getúlio Vargas outorgando uma Carta Constitucional, prometendo que ela seria submetida ao "referendum" popular, o que jamais ocorreu. Curiosamente, embora o ditador tivesse poderes absolutos aplicava-se a Constituição para alguns efeitos, tendo havido até mesmo algumas reformas constitucionais, também outorgadas por decreto do ditador. Outro aspecto curioso era que a Carta Outorgada de 1937, embora produto de uma centralização absoluta do poder, afirmava que o Brasil continuava sendo um Estado Federal.

Em 1945 dá-se a queda de Getúlio Vargas e no ano seguinte uma Assembléia Nacional Constituinte aprova nova Constituição, reafirmando a organização federativa do Estado Brasileiro. Na prática, o Brasil voltou a funcionar como um Estado Federal, embora com um governo federal dotado de maiores competências e de muito mais recursos financeiros do que os governos estaduais. $\mathrm{E}$ mais uma vez ocorreram inúmeras inadequações, pois as regiões Norte e Nordeste, menos desenvolvidas economicamente e, em conseqüência, apresentando desníveis sociais muito acentuados, continuaram intocadas. Por outro lado, não obstante afirmar enfaticamente a prevalência da livre iniciativa, a própria Constituição criou vários instrumentos para intervenção do Estado na ordem econômica, visando, sobretudo, promover a redistribuição dos recursos financeiros, por meio do planejamento da economia e da concessão de incentivos aos investimentos que fossem feitos nas regiões menos desenvolvidas.

Mas os desníveis sociais e regionais continuaram fomentando descontentamentos e estimulando movimentos favoráveis a profundas reformas estruturais. Isso levou ao acirramento das lutas políticas, culminando com a renúncia do Presidente Jânio Quadros, em 1961, após alguns meses de governo, por motivos que até agora não foram esclarecidos de modo 
coerente. Em seguida, num ambiente de conturbação crescente, - Vice-Presidente João Goulart é obrigado a aceitar a substituição do Presidencialismo pelo Parlamentarismo para que lhe fosse dada posse na Presidência da República. Em pouco tempo, entretanto, consegue nova emenda constitucional conseqüente de um plebiscito que deveria ser realizado no término de seu mandato, mas que se realizou mais de dois anos antes do tempo previsto - restaurando o Presidencialismo, o que, afinal, precipitaria sua derrubada por um movimento militar iniciado em 31 de março e já consumado em $10^{\circ}$ de abril de 1964. Pouco depois, em 9 de abril de 1964, foi revogada a Constituição de 1946, por forma indireta. Com efeito, implantado um governo militar, este publicou um conjunto de ordens a que denominou Ato Institucional, dizendo, entre outras coisas, que continuava em vigor a Constituição, mas reservando-se, ao mesmo tempo, ampla margem de ação arbitrária.

Desde então não ocorreu qualquer modificação substancial. Em 1967 foi aprovada uma nova Constituição, pelo Congresso Nacional. O projeto fora elaborado pelo governo militar e o Congresso, chamado a atuar como Assembléia Constituinte, quase nada influiu, conseguindo apenas que fossem aceitas algumas emendas propostas por seus membros. Mais uma vez se afirmava que o Brasil continuava sendo um Estado Federal, embora com um governo fortemente centralizado e dotado de poderes absolutos. Finalmente, em 1969, por motivos a que os políticos e o povo estiveram alheios, surgiu nova Carta Outorgada, assinada por três chefes militares que assumiram o governo em substituição ao Marechal Costa e Silva. Essa nova Carta recebeu a denominação oficial de Emenda Constitucional n. ${ }^{\circ} 1$, com evidente inadequação, pois uma Constituição só pode ser emendada por forma nela mesma prevista e na outorga da Carta de 1969 não se levou em conta o processo de emenda previsto na Constituição de 1967, o que demonstra que esta foi simplesmente posta de lado, não obstante o novo texto repetir muitos de seus dispositivos.

E também no documento de 1969 persiste a afirmação de que o Brasil é um Estado Federal, embora sob muitos aspectos fundamentais não funcione como federação, havendo no próprio texto constitucional inúmeros dispositivos claramente incompatíveis com uma organização federativa. Apesar disso, porém, formalmente o Brasil é uma República Federativa, estando expressamente proibida até mesmo a discussão de emendas constitucionais tendentes à abolição da Federação ou da República. 
Como se verifica, o descompasso entre as afirmações formais da Constituição e o que ocorre na prática ainda é uma das características do sistema jurídico-social brasileiro. Tal desencontro, que vem desde a primeira Constituição, de 1824, e não foi eliminado pelas várias Constituições posteriores, é, sem dúvida, um dos fatores responsáveis pela instabilidade política, que tem sido uma constante na vida brasileira. Isso autoriza a crença em que haverá maior possibilidade de uma ordem política e social estável quando houver uma Constituição autêntica, que leve em conta as características globais da realidade social, fixando meios adequados para a redução substancial dos desníveis sociais e regionais.

\section{Bibliografia.}

Bello, José Maria, História da República, São Paulo, Cia. Editora Nacional, 1972 (6. ${ }^{\mathrm{a}}$ ed.).

Dallari, Dalmo DE ABreu, Novos Pólos Administrativos Afetando a Federação Brasileira (In As Tendências Atuais do Direito Público, de Paulo Bonavides e outros), Rio de Janeiro, Ed. Forense, 1976.

Faoro, Raymundo, Os Donos do Poder (2 vols.), Porto Alegre, Ed. Globo (em colaboração com a Universidade de São Paulo), 1975 (2. ${ }^{a}$ ed.).

Ferreira, Waldemar Martins, História do Direito Constitucional Brasileiro, São Paulo, Ed. Max Limonad, 1954.

Franco, Afonso Arinos de Melo, Direito Constitucional, Rio de Janeiro, Ed. Forense, 1976.

Keith, Henry H., e EDWArds, S. F. (Organizadores), Conflito e Continuidade na Sociedade Brasileira, Rio de Janeiro, Ed. Civilização Brasileira, 1970.

Mota, Carlos Guilherme (Organizador), Brasil em Perspectiva, São Paulo, DIFEL, 1974 (5. ${ }^{\mathrm{a}}$ ed.).

Prado Jr., CaIo, História Econômica do Brasil, São Paulo, Ed. Brasiliense, 1949 (2. ${ }^{\mathrm{a}}$ ed.).

Torres, João Camillo de Oliveira, A Formação do Federalismo no Brasil, São Paulo, Cia. Editora Nacional, 1961.

Viana, Hélo, História do Brasil (3 vols.), São Paulo, Ed. Melhoramentos, 1972. 